\title{
A Power Supply Consists of the DC-DC Boost Converter and a Full-Bridge Inverter Circuits for a PZT Liquid Pump
}

\author{
Chaoying Liu, Shiuan-Ho Chang, Ying Jun Chen, Xiahui Wang, Xin Yu, Z. Y. Xu, and Min Zhou
}

\begin{abstract}
Nowadays, most of the driving powers of PZT ( lead zirconate titanate ) pumps are large, less efficient, and high power consumption. This paper presents a new type of a driving power supply composed of the step-up inverter for a PZT liquid pump. In order to provide a square wave of $\pm 40 \mathrm{~V}$ and $50 \mathrm{~Hz}$ for a PZT liquid pump, this design used the MC34063 and NE555 integrated circuits to respectively fabricate a DC-DC boost circuit as well as a full-bridge inverter circuit. The performance of the driving power supply is verified by the theoretical statement and practical test. Besides, the liquid pump is composed of a PZT, elastomer pump valve, and PET ( Polyethylene terephthalate ) pump body, while the power, flow rate, body size and weight of the pump are $1 \mathrm{~W}, 800 \pm 5 \% \mathrm{ml}$ $\mathrm{min}^{-1}, 50 \times 50 \times 10 \mathrm{~mm}$., $50 \mathrm{gw}$, respectively. Furthermore, the PZT liquid pump is suitable for various fluids such as water, soda, alcohol, etc.
\end{abstract}

Index Terms-Piezoelectric, boost converter, PZT, full-bridge inverter, power supply.

\section{INTRODUCTION}

With the progress of science and technology, the PZT liquid pump is a novel product that conforms to the trend of the times [1]-[5]. It is composed of the piezoelectric ceramic, PET ( Polyethylene terephthalate ) pump body, and an elastomer check valve. The PZT liquid pump has many advantages such as small size, low noise and power consumption, simple structure, easily being controlled, no electromagnetic interference and mechanical wear, and no maintenance [6]-[10]. It is a new type of product with energy saving and low carbon for the environmental protection. Additionally, the PZT liquid pump is widely used in various fields such as aquariums, landscaping, etc. The PZT pump is stabler than other pumps, and the flow rate of the liquid is related to the magnitude and frequency of the applied voltage [11]-[13]. Therefore, the liquid flow rate is able to be controlled through controlling the magnitude or frequency of the applied voltage to a PZT pump. The more stable the magnitude and frequency of the applied voltage is, the more

Manuscript received January 25, 2019; revised March 15, 2019. This work was supported by the Science Technology Project, 2012G031, Zhaoqing and the Science Technology Project 611612283, Zhaoqing University. The study was supported by JC Technological Innovation Electronics CO., LTD, Guangdong, PR China.

Chaoying Liu, Shiuan-Ho Chang, Ying Jun Chen, Xiahui Wang, Xin Yu, and Z. Y. Xu are with the College of Electronics and Electrical engineering, Zhaoqing University, Duanzhou District, Zhaoqing, Guangdong, PR China, 526061 (e-mail: 2446258235@qq.com, 1802186169@qq.com).

Min Zhou is with the Guangdong JC Technological Innovation Electronics CO., LTD (e-mail: 36671984@qq.com). accurate the controlled flow rate becomes. Because the external environment affects the stability of the PZT liquid pump, the performance of the driving power for the pump plays a vital role [14]-[16]. There are six main kinds of DC converters, i.e., Buck, Boost, Buck-Boost, Cuk, Zeta, and Sepic converters, while the Boost converter is used in this study. In addition, it is necessary for a PZT pump to transform the direct current (DC) into a alternating current (AC) with certain frequency, and thereby the inverter is applied to this study. Generally, according to the structures of the inverter circuits, the inverters can be classified into several types, namely, single-end, half-bridge, full-bridge, and push-pull inverters [17]-[19]. In order to provide a square wave of $\pm 40 \mathrm{~V}$ and $50 \mathrm{~Hz}$ for a PZT liquid pump, this work used the MC34063 and NE555 integrated circuits (IC) to respectively fabricate a DC-DC boost converter as well as a full-bridge inverter circuit. The full-bridge inverter is one of the high frequency inverters and has the advantages of simple circuit, controllable output, high conversion efficiency, and high output power. It has been widely used in many fields such as rotating-speed control of a motor, switching power supply, and frequency converter [20]-[22]. As well known, the square wave or sine wave can be applied in the control circuit of an inverter. On the basis of the simple design and easily being controlled, the control circuit of the square wave for an inverter is the development trend nowadays and it is used in this work. Finally, some practical pictures are used to certify this study.

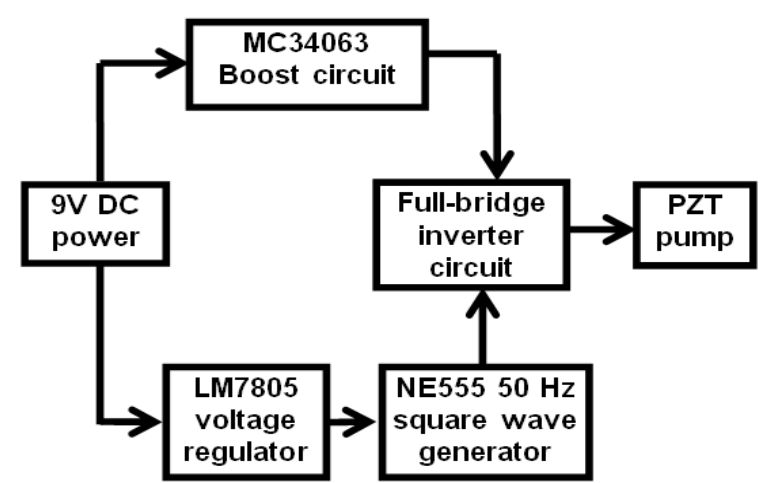

Fig. 1. A flowchart of generating a $40 \mathrm{~V}, 50 \mathrm{~Hz}$ AC voltage for a PZT liquid pump.

\section{EXPERIMENTAL}

A. Circuit Design of a Power Supply for a PZT Liquid Pump

Fig. 1 shows the flowchart of generating a square wave of 
AC $40 \mathrm{~V}, 50 \mathrm{~Hz}$ voltage for a PZT liquid pump. The input is a $9 \mathrm{~V}$ DC voltage provided by the lithium battery and the DC-DC boost converter ( MC34063) transfers from 9V to a higher DC voltage of 40V. Moreover, the voltage of 9V DC is adjusted to $5 \mathrm{~V}$ DC for the NE555 IC by a LM7805 regulator.

Subsequently, a full-bridge inverter circuit transfers from $40 \mathrm{~V} \mathrm{DC}$ to a square wave of $40 \mathrm{~V}, 50 \mathrm{~Hz}$ AC voltage through the NE555 integrated circuit. On the other hand, there are three main parts in Fig. 2, which illustrates a circuit diagram of a power supply. Firstly, for a MC34063 boost circuit, the chief electronic components are the comparator, logic gates, flip-flop, inductance, and capacitances. Secondly, the crucial electronic components are comparators, logic gates, and capacitances for a NE555 square wave circuit of $5 \mathrm{~V}, 50 \mathrm{~Hz}$. Finally, the full-bridge inverter circuit is composed of four important BJTs (bipolar junction transistors).

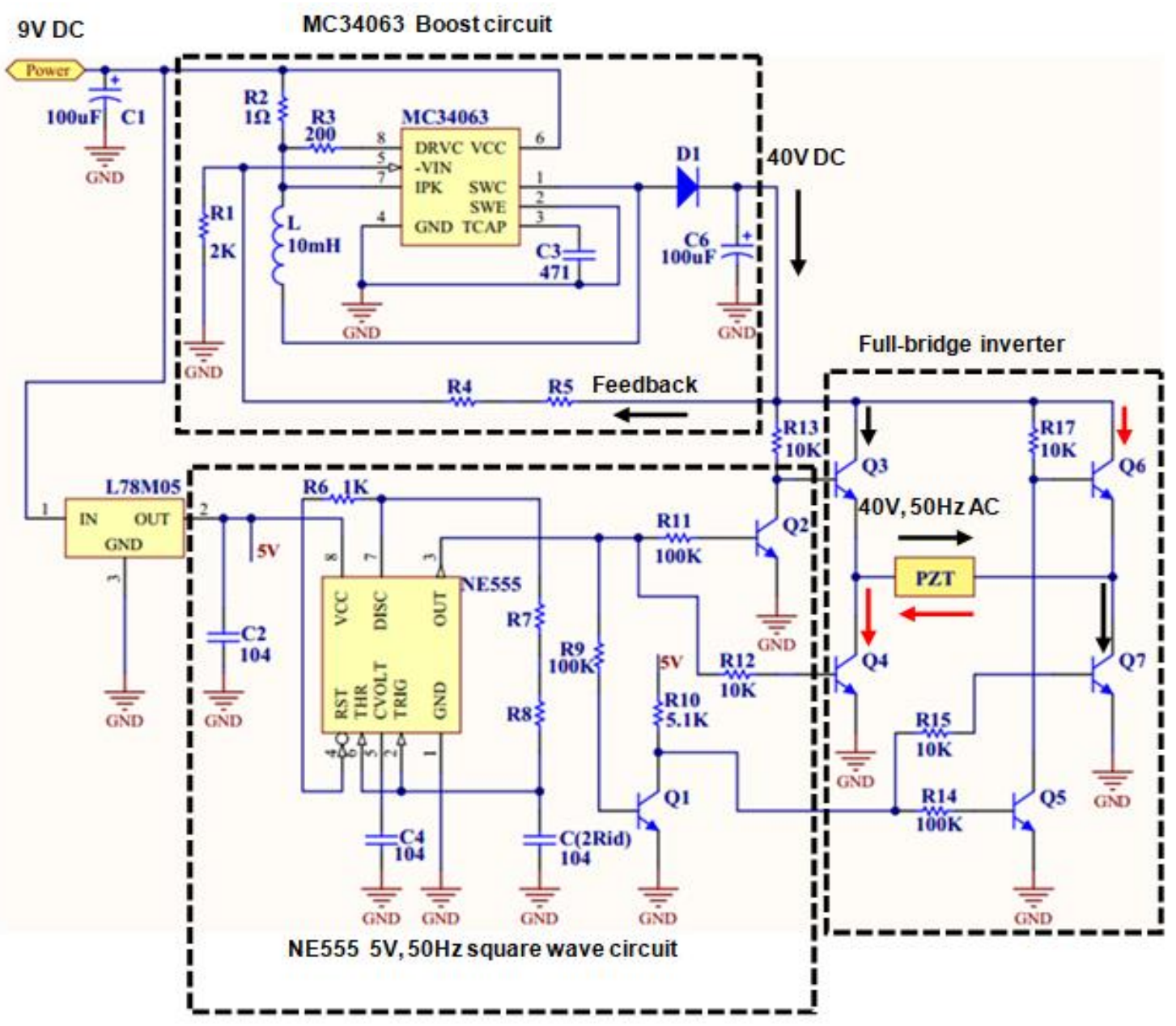

Fig. 2. A circuit diagram of a power supply composed of the boost and inverter circuits.

\section{B. The Structure of a PZT Liquid Pump}

A PZT of $0.3 \mathrm{~mm}$ thick film, which is coated a silver layer on both upper and lower surfaces, is pasted onto a copper sheet to generate a PZT oscillator, as revealed in Fig. 3 (a). The $\mathrm{Sn}$ is welded on the lower and upper surfaces of the PZT oscillator to form the electrodes through which the exciting AC voltage of $50 \mathrm{~Hz}, 40 \mathrm{~V}$ is applied to the PZT. Besides, Fig. 3 (b) illustrates the bottom part of the pump body made of the PET with an O-ring, an inlet valve of the elastomer and an outlet hole. Relatively, the top PET part only contains an O-ring, as shown in Fig. 3 (d). The PZT oscillator is put into the bottom part and then covered by the top part to mold a PZT pump, as illustrated in Fig. 3 (c) - (e). At the same time, a liquid chamber is generated between the bottom part of the pump and the PZT oscillator. The volume and pressure of the liquid chamber change with the compressing or stretching force built from the PZT.

\section{THE OPERATIONAL PRINCIPLE OF A FULL-BRIDGE INVERTER CIRCUIT}

Because the operational principles of MC34063 boost and NE555 square wave circuits are basic in the digital electronics, this study only presents the operational principle of a full-bridge inverter circuit. As shown in Fig. 2, the full-bridge inverter mainly consists of the BJTs, Q3, Q4, Q6, and Q7, whereas the driving circuit is composed of the BJTs, Q1, Q2, Q5 as well as some resistances. All the BJTs revealed in Fig. 2 are type NPN, and the output voltage $V_{1 B}$ of the NE555 IC is a square wave of $5 \mathrm{~V}, 50 \mathrm{~Hz}$, which is the same as $\mathrm{V}_{1 \mathrm{C}}$ except a phase difference of $180^{\circ}$. Besides, the collector voltage of 40V DC for both Q3 and Q6 is from a MC34063 DC-DC boost circuit. When the $\mathrm{V}_{1 \mathrm{~B}}$ is at a high level (then the

$\mathrm{V}_{1 \mathrm{C}}$ is at a low level ), the Q2 and Q4 switches turn on. At the same time, the Q3 switch turns off as the base voltage is at 
a low level through Q2. Likewise, the Q5 and Q7 switches turn off because the $\mathrm{V}_{1 \mathrm{C}}$ is at a low level, while the Q6 turns on as the base voltage is at a high level. Hence, the Q4, Q6 switches turn on but the Q3, Q7 switches turn off in the full-bridge inverter. This leads the voltage of $40 \mathrm{~V} \mathrm{DC}$ transfers from the collector of Q6 to the ground through a PZT and Q4. In contrast, when the $\mathrm{V}_{1 \mathrm{~B}}$ is at a low level ( then the $\mathrm{V}_{1 \mathrm{C}}$ is at a high level ), the Q4, Q6 switches turn off but the Q3, Q7 switches turn on. The voltage of 40V DC transfers from the collector of $\mathrm{Q} 3$ to the ground through a PZT and Q7. Therefore, the PZT gets a voltage of $40 \mathrm{~V} \mathrm{AC,}$ $50 \mathrm{~Hz}$ and the frequency depends on the NE555 square wave circuit.
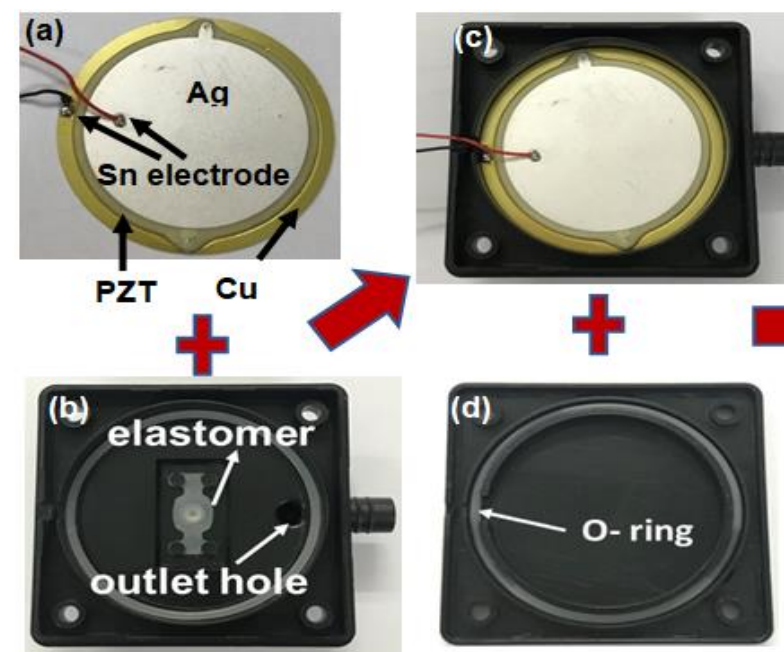

(e)
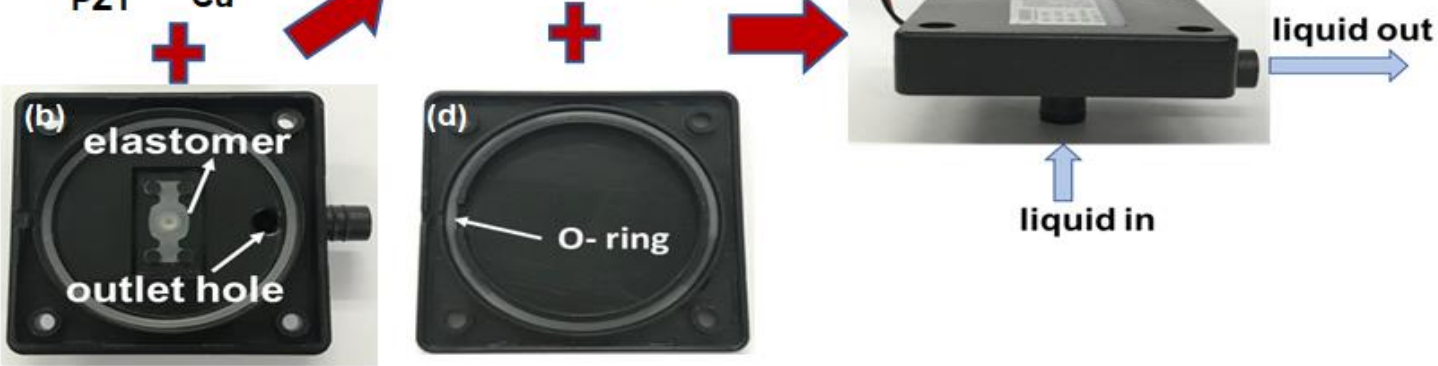

Fig. 3. Pictures of the parts of a PZT pump : (a) A PZT oscillator (b) Bottom part (c) A PZT oscillator in the bottom part (d) Top part (e) A forming PZT pump.

\section{RESULTS AND DISCUSSION}

Fig. 4 reveals the voltage waveform applied to a PZT liquid pump. The voltage waveform is a square wave of $\mathrm{AC}$ $40 \mathrm{~V}$ and $50 \mathrm{~Hz}$, which verifies the circuit diagram designed for a power supply of a PZT liquid pump. However, the waveform has a small spike every half a period, resulting in a poor voltage waveform. The spikes may be caused by the parasitic capacitances and inductances in a NE555 IC. Fig. 5 shows a picture of the PZT liquid pump and the driving circuit with a lithium battery. The MC34063 and NE555 ICs are obviously displayed in the driving circuit, that is simple design and low cost.

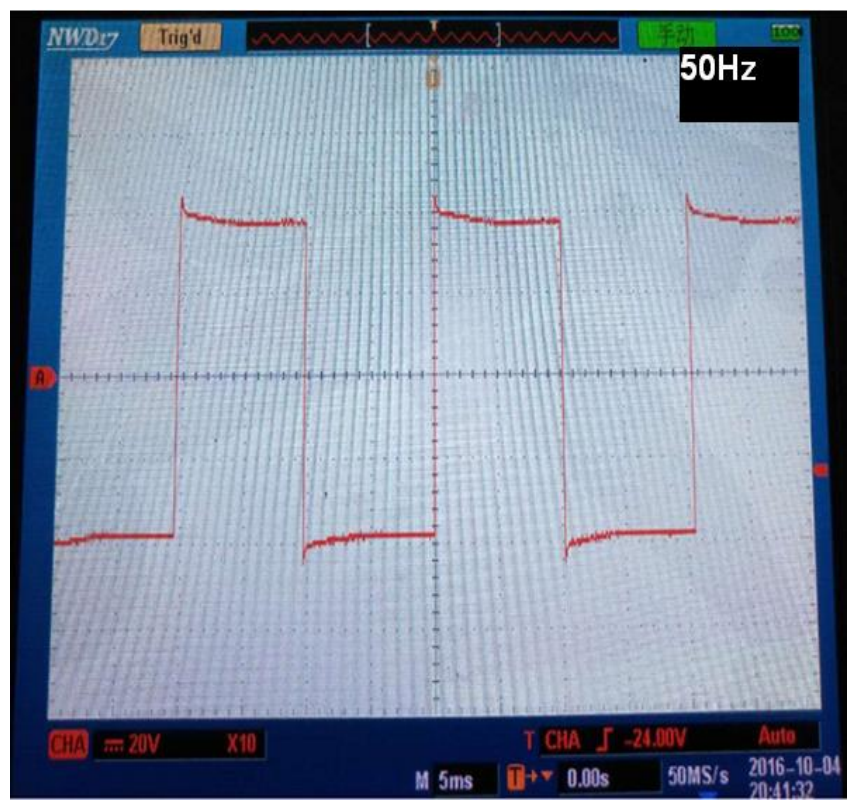

Fig. 4. An image of the voltage waveform applied to the PZT shown in Fig. 2.

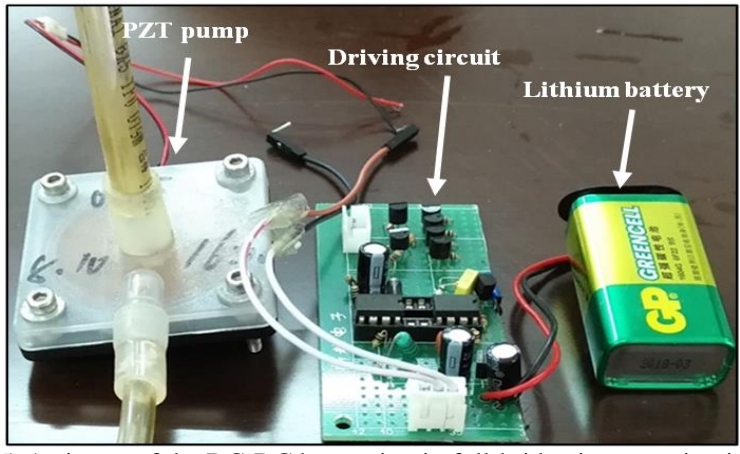

Fig. 5. A picture of the DC-DC boost circuit, full-bridge inverter circuit, and a PZT pump.

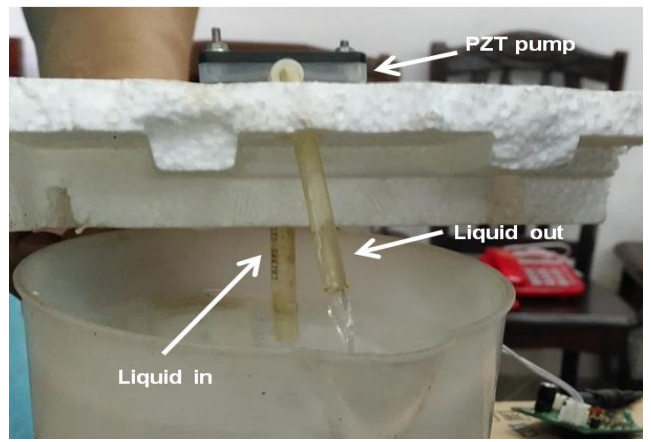

Fig. 6. A picture of a running PZT liquid pump.

As illustrated in Fig. 6, a picture of a running PZT liquid pump, the power consumption and flow rate respectively are $1 \mathrm{~W}$ and $800 \pm 5 \% \mathrm{ml} \mathrm{min}-1$. This picture states that the designed driving circuit successfully is applied to the PZT liquid pump.

\section{CONCLUSIONS}

This study successfully presents a power supply composed 
of the DC-DC boost converter and a full-bridge inverter circuits for a PZT liquid pump, which possesses many advantages such as simple structure, small size, low power consumption, fast response speed, stable output waveform and strong driving capability.. There are three main parts in the driving circuit, namely, a MC34063 boost circuit, a NE555 square wave circuit, and a full-bridge inverter circuit. Through the driving circuit, the PZT liquid pump gets a voltage of $40 \mathrm{~V} \mathrm{AC}, 50 \mathrm{~Hz}$ and has a high flow rate of $800 \pm$ $5 \% \mathrm{ml} \mathrm{min}{ }^{-1}$. According to the applied voltage or frequency to a PZT pump, the flow rate of the fluid is able to be controled. A filter circuit will be coupled into the driving circuit to improve the voltage waveform applied to a PZT pump in the future.

\section{REFERENCES}

[1] G. M. Cheng, P. Li, P. Zeng, J. S. Dong, and F. F. Sun, "Piezoelectric pump used in bionic underwater propulsion unit," J. Bionic Eng., vol. 4, pp. 159-164, 2007.

[2] H. H. Kim, J. H. Oh, J. N. Lim, K. J. Lim, and D. H. Park, "Design of valveless type piezoelectric pump for micro-fluid devices," Procedia Chemistry, vol. 1, pp. 353-356, 2009.

[3] X. Y. Wang, Y. T. Ma, G. Y. Yan, D. Huang, and Z. H. Feng, "High flow-rate piezoelectric micropump with two fixed ends polydimethylsiloxane valves and compressible spaces," Sensor Actuat A-Phys, vol. 218, pp. 94-104, 2014.

[4] Y. Wang and W. Huang, "A piezoelectric motor with two projections using two orthogonal flexural vibration modes," Sensor Actuat A-Phys, vol. 250, pp. 170-176, 2016.

[5] S. Wang, W, Rong, L. Wang, Z. Pei, and L. Sun, "A long range piezoelectric rotary motor with continuous output: Design, analysis and experimental performance," Sensor Actuat A-Phys, vol. 263, pp. $179-187,2017$

[6] X. F. Leng, J. H. Zhang, Y. Jiang, J. Y. Zhang, X. C. Sun, and X. G. Lin, "Theory and experimental verification of spiral flow tube-type valveless piezoelectric pump with gyroscopic effect," Sensor Actuat A-Phys, vol. 195, pp. 1-6, 2013

[7] Y. Liu, W. Chen, P. Feng, and J. Liu, "A linear piezoelectric actuator using the first-order bending modes," Ceramics International, vol. 39, pp. S681-S684, 2013.

[8] S. Yang, X. He, S. Yuan, J. Zhu, and Z. Deng, "A valveless piezoelectric micropump with a Coanda jet element," Sensor Actuat A-Phys, vol. 230, pp. 74-82, 2015.

[9] S. Ho and S. Jan, "A piezoelectric motor for precision positioning applications," Precision Engineering, vol. 43, pp. 285-293, 2016.

[10] P. H. Cazorla, O. Fuchs, M. Cochet, S. Maubert, G. L. Rhun, Y. Fouillet, and E. Defay, "A low voltage silicon micro-pump based on piezoelectric thin films," Sensor Actuat A-Phys, vol. 250, pp. 35-39, 2016.

[11] Z. Zhang, J. Kan, S. Wang, H. Wang, J. Wen, and Z. Ma, "Flow rate self-sensing of a pump with double piezoelectric actuators," Mech Syst. Signal, vol. Pr 41, pp. 639-648, 2013.

[12] P.-H. Cazorla, O. Fuchs, M. Cochet, S. Maubert, G. Le Rhun, P. Robert, Y. Fouillet, and E. Defay, "Piezoelectric micro-pump with PZT thin film for low consumption microfluidic devices," Procedia Engineering, vol. 87, pp. $488-449,2014$.

[13] J. S. Dong, R. G. Liu, W. S. Liu, Q. Q. Chen, Y. Yang, Y. Wu, Z. G. Yang, and B. S. Lin, "Design of a piezoelectric pump with dual vibrators," Sensor Actuat A-Phys, vol. 257, pp. 165-172, 2017.

[14] P. Sanchis, A. Ursæa, E. Gubía, and L. Marroyo, "Boost DC-AC Inverter: A new control strategy," IEEE Trans Power Electron, vol. 20 pp. 343-353, 2005

[15] G. Rong, L. Zhigang, and A. Q. Huang, "A family of multimodes charge pump based DC-DC Converter with high efficiency over wide input and output range," IEEE Trans Power Electron, vol. 27, pp. 4788-4798, 2012.

[16] J. C. Rosas-Caro, J. C. Mayo-Maldonado, A. Valderrabano-Gonzalez, F. Beltran-Carbajal, J. M. Ramirez-Arredondo, and J. R. Rodriguez-Rodriguez, "DC-DC multiplier boost converter with resonant switching," Electr. Pow. Syst. Res., vol. 119, pp. 83-90, 2015.

[17] W. R. Anis, "Stepped sine wave DC/AC inverter. I. Theoretical analysis," Sol. Energ. Mat. Sol. C, vol. 28, pp. 123-130, 1992.
[18] A. El Magri, F. Giri, A. Abouloifa, and F. Z. Chaoui, "Robust control of synchronous motor through AC/DC/AC converters," Control Eng. Pract., vol. 18, pp. 540-553, 2010.

[19] K. M. Tsang and W. L. Chan, "27-Level DC-AC inverter with single energy source," Energy Convers Manage, vol. 53, pp. 99-107, 2012.

[20] J. D. Zhu, J. Liang, Y. Lu, and C. H. Zhang, "A new IGBT control and drive circuit for high-power full-bridge inverter for electrostatic precipitators," J. Electrostat, vol. 71, pp. 235-239, 2013.

[21] Y. N. Tong, C. L. Li, and F. Zhou, "Synchronization control of single-phase full bridge photovoltaic grid-connected inverter," Optik, vol. 127, pp. 1724-1728, 2016.

[22] H. Fathabadi, "Novel high efficiency DC/DC boost converter for using in photovoltaic systems," Solar Energy, vol. 125, pp. 22-31, 2016.

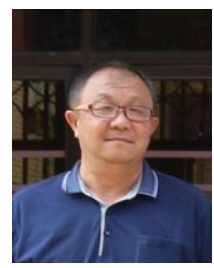

Chaoying Liu is with College of Electronics and Electrical Engineering, Zhaoqing University. The author's major is power circuit design. He received the $\mathrm{PhD}$ degree in Department of Material Processing Engineering, South China University of Technology, China, in 2011

$\mathrm{He}$ is a professor at the Zhaoqing University, in Guangdong, China. His research interests concern: power circuit design.

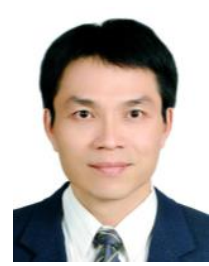

Shiuan-Ho Chang is with College of Electronics and Electrical Engineering, Zhaoqing University. The author's major is optoelectronics.

$\mathrm{He}$ received the $\mathrm{PhD}$ degree in Institute of Microelectronic, Department of Electrical Engineering, National Cheng Kung University, Tainan, Taiwan, R.O.C., in 2006.

$\mathrm{He}$ is an associate professor at the Zhaoqing University, in Guangdong, China. His research interests concern: optoelectronics, electronics, physics.

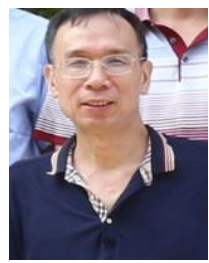

Ying Jun Chen is with College of Electronics and Electrical Engineering, Zhaoqing University. The author's major is the analyses of digital circuit, high frequency circuit, and television theory. $\mathrm{He}$ is a professor at the Zhaoqing University, in Guangdong, China. His research interests concern: circuit analysis.

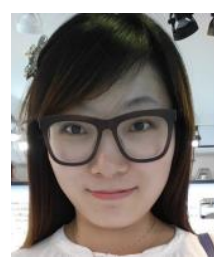

Xiahui Wang is with College of Electronics and Electrical Engineering, Zhaoqing University. The author's major is optoelectronics.

She received received her BS degree in environmental engineering from Henan University of Science and Technology, Luoyang, China, in 2009, and her MS degree from Wuhan University of Technology, Wuhan, China, in 2012. She also received her another MS degree in 2014 and $\mathrm{PhD}$ degree in polymer nanoscience and technology at Chonbuk National University, Jeonju, South Korea, in 2017. Currently she is working in Zhaoqing University. Her research interests include polarization converters, lenses, and optical switches, and other adaptive photonic devices.

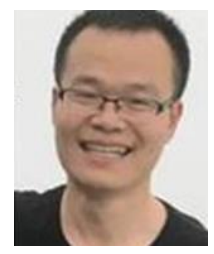

Xin $Y \mathbf{u}$ is with College of Electronics and Electrical Engineering, Zhaoqing University. He received the Bachelor degree in Zhaoqing University in 2018.

Z. Y. Xu is with College of Electronic Information and Mechatronic Engineering, Zhaoqing University. The author's major is new material research.

He received the $\mathrm{PhD}$ degree in University of Electronic Science and Technology of China, in 2016.

$\mathrm{He}$ is a senior engineer at the Zhaoqing University, in China. His research interests concern: new materials.

Min Zhou is a senior engineer at JC Technological Innovation Electronics CO., LTD, in Guangdong, China. His research interests concern piezoelectric ceramic. 